\title{
The role of different stakeholders in Ethiopia in the improvement of educational quality
}

\author{
Kufi, Endalew Fufa $₫$ \\ Central University College, Addis Ababa, Ethiopia (frankologis@yahoo.com)
}

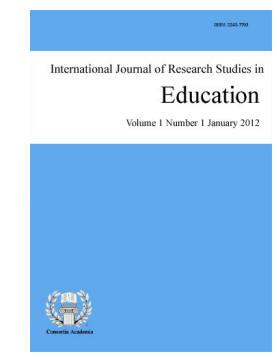

Accepted: 30 May 2012

ISSN: 2243-7703 Online ISSN: 2243-7711

OPEN ACCESS

\section{Abstract}

Quality education is an everyday quest in Ethiopia, for both the educated and the lay. It has also become an issue of big scrutiny among both government and private institutions. But, the type and extent of roles to be played by different stakeholders are not yet clearly ascertained. One of the centers of attention in Ethiopia is health institution under the private holding. In this research, hence, attention was given to the role of stakeholders in improving education quality in private health institutions. For the materialization of the research, four private colleges were purposively selected as target research sites according to their ease for access of data. Such were Rift-Valley College, Central College of Health, Deborah and Keamed. Target informants were selected from among internal and external stakeholders. Accordingly, the informants among internal stakeholders were 40 students, 20 teachers and four officers. Likewise, four health professionals in the private health center were purposively chosen as data providers from among external stakeholders. The research data were collected in the form of responses to questionnaire from students and teachers; and, in the form of interview data from officers. After thorough analysis of the data, the researcher has come up with the findings that, internal stakeholders had stronger curricular and evaluative roles than external ones. Even among internal stakeholders, officers had the strongest role of making instructional and programmatic decisions while the chief ones, students, had the least. Overall, shortages were observed in terms of inter-collegial experiential exchange, research ties and human-resource exchange among the internal and the external stakeholders. So, the researcher has come to recommend the presence of workable ties with both internal and external stakeholders in order for the concerned health institutions to develop both instructional and field quality.

Keywords: internal stakeholders; external stakeholders; education quality; private health institutes; health profession 


\section{The role of different stakeholders in Ethiopia in the improvement of educational quality}

\section{Introduction}

Quality education is both a personal and social priority that marks the present and prospect of people and nations. Regarding this, Teshome (2007) states that, as far as individual learners are a part of the society, and the society benefits from them, higher educational institutions and the society must work hand-in-hand in order to ensure the quality of education in the former and services which follow in the latter. As one of the crucial elements of humanity, health is central for socio-economic sustainability, and hence, it becomes essential to look into its quality. In today's trend of life when prevention is pronounced much more than cure, health institutions and their students need to emphasize quality as well as quantity, the rationale being quality education relevant for better and secure life and vocations. From this, it can be traced that, research on the quality of education for health professionals, more specifically in private higher institutions, is indispensable since how people of the vocation are educated and the experiences they gain the way through have uttermost effects on their professional qualities (Heidgerken, 2004).

A certain subscription denoted that, millions of people in poor countries get low-quality health care, or are forced to go without it altogether. Fees are too high, hospitals and clinics are too few, and lack of medical staff means people struggle to get treated (Oxfam International, 2010). Here, low quality health care is pronounced as one of the challenges in poor countries which may be entailed by lack of quality health education or failure to afford the required service. The subscription exemplifies further that, every minute, a woman with no medical care dies in pregnancy or childbirth. Every hour, 300 people die of an AIDS-related illness. Every day, 4,000 children die of diarrhea caused by dirty water as well. These examples indicate the necessity for health education. Millions of people in poor countries get low-quality health care, or are forced to go without it altogether. Fees are too high, hospitals and clinics are too few, and lack of medical staff means people struggle to get treated. Moreover, it has become an everyday question now to discuss quality education provision in government and private institutions in Ethiopia and elsewhere, the rationale being that, quality education is both the cause and the effect of quality services rendered to society in terms of social, economic, health and governance or administrative realms. A certain publication on education quality indicators in Ontario, under the short title "Completing the picture: The Education Quality Indicators Framework" states the following:

Student achievement results have always been considered key indicators of educational quality,
and student scores on large-scale assessments are the subject of public interest. However, test
scores can be interpreted meaningfully only in the context of the system that produced them.
Understanding and evaluating the quality of education requires not just numerical values or
quantitative result measures such as achievement, but a more comprehensive picture of the
unique and complex characters of schools, boards and the province. (Source:
http://www.eqao.com)

From the above citation, it is clear that, indicators of quality education cannot solely be seen from the academic standpoint but also from environmental, team-oriented and inclusive ventures of the community to be beneficiaries. In that, the process of education has three clearly set phases to go through, such being input, process and output to which the stakeholders should react either negatively or positively. The input aspect of education is set in the form of properly qualified human resource, well-adjusted material environment, and clearly and objectively arranged technical backup and well-scheduled provision foreseen effectively. To this effect, the human communication aspect is of uttermost and consistent importance, be it in intra-organizational or inter-organizational form. The process aspect deals with organization, staffing and directing and controlling of the resources, and, thereby, making the right use of resources in the right place of concern. The integrated effort of different stakeholders becomes more magnificent in the process, as plans and organized resources are put to 
The role of different stakeholders in Ethiopia in the improvement of educational quality

action. Such a process is integral, as it involves the role of different agents and effectual as the presence or absence of a certain stakeholder has a remarkable effect on the success/failure of the field in question.

Even though it senses premature to imply the absence to bring direct blockhead on the success of a certain education program, it can, somehow, have a deterring effect. The output aspect deals with the justification of achievement in line with the expected quality standard in knowledge, skills and attitude as per the requirements of human learning and education. With this view, what students bring to the realm of education, how resources are put to action, the type of evaluation held and the duration of follow-up , the very provision standard and consistency of provision have their roles in due accord. This research surveyed the role of varying stakeholders in enriching quality education in the health stream by Ethiopian Private Higher Education Institutions with a view to identifying their positive contributions and validating the inputs of such a co-action. Hence, this research looked into the role of different stakeholders in improving education quality in private health institutions of Ethiopia, with particular emphasis to private colleges and institutions in Adama City and Nekemte Town.

\title{
1.1 Statement of the problem
}

One of the bottleneck phenomena in education is the mismatch between principle and practice. In principle, education is believed to be the tool for the improvement of society, not just a sector, and the outputs of education reach almost all sectors. Among the actors leading to educational infertility is the missing role of stakeholders, in that, graduates never get due information about the work environment before they are graduated from a college/university. Host institutes also lack the ground to improve their programs unless they work with the different stakeholders concerned. But, the roles different societal sectors have and the contributions they owe education so far may not be as magnificent as their demands for educated human resource in Ethiopia. In cases where education is a personal virtue and means of fulfilling one's desires alone, this may not be a big deal because it is up to the person to cultivate the right knowledge, skills and attitudinal assets s/he thinks to be effectual to him/her to attain her/his goals. But, in situations where the educated human resource is destined to serve the society, like Ethiopia, it is a necessity to consider the roles of the stakeholders which can be in terms of economic, socio-cultural, ideological and/or even religious ties. Such involvement as from different societal sectors can have a very great contribution for well-oriented foundation of education and clear flow of tasks based on the existing demand known ahead; and, thereby, working out the quality of output in line with the demand in the field. It is the presence in depth and practicality in progress of the different stakeholders' roles that counts as indicator of quality education if the input-process-output flow is to be effective.

The following citation brings us the idea that, increase in educational provision in private sectors with diverse expanse and degrees has brought with it the need to give attention to functional aspects. The same document presents two quality assurance mechanisms to be set both at national and institutional levels, as in the succeeding lines:

\begin{abstract}
Internal quality assurance (IQA) refers the policies and mechanisms for ensuring fulfillment of purposes, as well as the standards that apply to higher education in general, or to the profession or discipline in particular. External quality assurance (EQA) refers to the actions of an external body, possibly a quality assurance agency, which assesses the operation of the institution or its programs, to determine whether it is meeting the agreed standards. EQA systems include accreditation, assessment or audit (ibid).
\end{abstract}

In Ethiopia, according to Teshome (2005), regardless of the daring need to create exchange channels between education institutions and the different stakeholders, there is no well-built interchange due may be to absence of programmed system of communication or systems that are hard to take to practice. Such a rift can certainly block the smooth exchange of experiences in societal sectors to the realm of education, thereby making educational institutions aloof and non-directional in their production of human resources. Such a case may be true with private health institutions in Ethiopia, which produce human resources who are expected to work in the 
Kufi, E. F.

health sector. Hence, there emerges necessity to study how far different stakeholders contribute for the provision of quality education in the health stream, especially to the PHIs in Ethiopia.

This research focused on answering the following basic questions:

1. How do private higher institutions communicate their curricular, technical and methodological status, and needs to the different stakeholders?

2. How do the different stakeholders react to education provision by private health institutions and the type of communication there unto?

3. What are major factors which negatively affect the route of stakeholders?

4. How collaborative and consistent are efforts made by the different stakeholders to err out defects in provision and assure quality of health training and education in the respective institutions?

\subsection{Significance of the study}

This research will be of value to private health institutions in terms of workable findings which will enrich interaction with stakeholders. It will also be of beneficence to the stakeholders in that; it sharpens their interaction to private health institutions and widens their horizon of contribution between the two. This research will also direct quality assurance agency to base its decisions on the timely and pertinent data from the interplay of different resources such as human, material, financial, technical and time with respect to the dynamic feature of health training and education.

\subsection{Limitation of the study}

This research faced certain limitations which made it inconclusive and relatively shorthanded. The first limitation was that, not all questionnaires returned to which effect the researcher was forced to redistribute the questionnaire paper to some sites, especially to teachers and students in Health College of Deborah, Nekemte. This may have had some shrinkage in the data composure. The other goes to the lapse of time the research took till presentation due to inconveniency on the part of the host university. Since research is developmental, responses may have shown internal changes as the researcher held the study repeatedly. So, the research may have had some aspects which may be complemented directly or retested through further scrutiny normally and unequivocally.

\section{Literature reviews}

\subsection{Identity and role of stakeholders}

Stakeholders are all of the people that are in any way affected by the new product or service. Since the organization will rely on various stakeholders prior to developing the project plan where roles and responsibilities are typically defined, it is important to understand the roles and responsibilities early in the process. Members of society, citizens of state, and people of faith, and autonomous individuals who are able to fulfill their various specific creaturely functions with initiative, confidence, cooperation and innovation constitute stakeholder roles (Cadora, 2008). In this respect, stakeholders are individuals or entities who stand to gain or lose from the success or failure of a system or an organization. Gross and Godwin (2005) identify education's stakeholders as parents, students, alumni, administrators, employers and communities.

\subsection{Stakeholders' role in education}

The fact that a school or a university opens up a program does not imply that it controls everything on 
The role of different stakeholders in Ethiopia in the improvement of educational quality

close-door bases. Since the source and user of education is the society, initial set up of education must be done cognizant of the usability of the fields in question and practices underlying each. The role of different stakeholders and their contributions for an education sector are essentially important as a certain USAID working paper presents.

\begin{abstract}
Stakeholder collaboration in the definition, implementation, measurement, and evaluation of education quality improvement projects arguably increases the likelihood that the resulting policy will more effectively meet the needs of various beneficiaries and donors, be judged meaningful and successful by a wide range of stakeholders, have fewer unintended consequences, and be more sustainable. Participatory approaches also support democratic principles and efforts to move from top-down to partnership models of international development.
\end{abstract}

The first step in the process of stakeholder engagement is stakeholder identification-determining who your project stakeholders are, and their key groupings and sub-groupings. (Remember that certain stakeholder groups might be pre-determined through regulatory requirements) From this flows stakeholder analysis, a more in-depth look at stakeholder group interests, how they will be affected and to what degree, and what influence they could have on your project. The answers to these questions will provide the basis from which to build your stakeholder engagement strategy. Here it is important to keep in mind that not all stakeholders in a particular group or sub-group will necessarily share the same concerns or have unified opinions or priorities.

\title{
2.3 Attribute of stakeholders
}

Stakeholders are categorized by their power and salience in a grid according to the following attributes: promoters who attach a high priority to the reform policy and whose actions can have an impact on the implementation of the policy; defenders, stakeholders who attach a high priority to the reform policy but whose actions cannot have an impact on the implementation of the policy; latents, whose actions can affect the implementation of the reform policy but who attach a low priority to this policy; and apathetics, whose actions cannot affect the implementation of the reform policy and who attach a low priority to this policy. According to Golden and Gawler (2005) stakeholders are all those who need to be considered in achieving project goals and whose participation and support are crucial to its success. Stakeholder analysis identifies all primary and secondary stakeholders who have a vested interest in the issues with which the project or policy is concerned. The goal of stakeholder analysis is to develop a strategic view of the human and institutional landscape, and the relationships between the different stakeholders and the issues they care about most.

\subsection{Stakeholders analysis}

This began during the eve of industrialism and continues to be used nowadays by firms and organizations to factor in stakeholder interests in order to enhance the enterprise's relationship with society and secure and better prospects of financial success (Brugha \& Varvasovszky, 2000). Stakeholder analysis is a process of systematically gathering and analyzing qualitative information to determine whose interests should be taken into account when developing and/or implementing a policy or program (Schmeer, 1999). Stakeholder analysis is the identification of the key stakeholders in the analysis and planning stage of a change process, and an assessment of their interests and the way in which these interests are likely to affect this process. It results in deciding whom to involve in which way in the analysis and planning (tentatively in the change implementation) process.

Colling and Harvey (1995) propose that, external scrutiny of operations should adopt an approach that ensures accountability, enhances quality, is practical, efficient, and effective and offers a degree of autonomy. The writer Asserts also that, putting continuous quality improvement into practice in higher education requires 
Kufi, E. F.

the implementation of key principles of procedure and practical team approaches which are currently far from endemic across institutions, thereby, describing and explaining how the identification of specific roles and responsibilities within academic teams can provide one way of successfully establishing the link between quality control, assurance and assessment and the process of continuous quality improvement in the provision of higher education.

\section{Research methodology}

This research took a descriptive survey design treating systems of communication between private health institutions and the stakeholders, ways of reaction, affective factors, rate of improvement attempted to bring quality and consistency of feedback provision on the part of the latter.

\subsection{Population of the Research}

Sources of data were both internal and external stakeholders. As literature denotes internal stakeholders are those who work within the school system on a daily basis and who largely control what goes on there. They include school staff, district staff, and the school boards. External stakeholders are those outside the school who have indirect contributions for the day-to-day work of the schools who have a strong interest in school outcomes but who do not directly determine what goes into producing those outcomes (Research Corporation, 2009).

\subsubsection{Internal Stakeholders}

Reference to internal stakeholders was important to get sufficient data regarding their roles in contributing directly for the improvement of curricular, administrative and general teaching-learning qualities of the lessons and endorsed practices. The internal stakeholders I dealt with in my research were teachers, students, deans and quality assurance officers in the selected private health colleges. The selection was based on convenience sampling for students, and purposive sampling for teachers and officers. Convenience sampling was believed to be essential for the selection of students because their will to be present to fill the questions was forethought to be crucial which otherwise could make the research process rigid and fictitious. The target of being purposive in selecting sample teachers and officers was experience and special position they had respectively. Teachers' experience was seen from the position of length of service years and task-shouldering.

\subsubsection{External Stakeholders}

It is obvious that, the contribution or roles different stakeholders play can vary from office to office. It can also vary from region to region. To cross the chill, the researcher took convenience sampling for the selection of the sites. In that, the researcher tilted to the maximum possibility situation to reach the regions for accessing bureau heads. Accordingly, the researcher contacted two officers in Nekemte Health Center and two others in Nekemte Hospital Administration. The session of interview was also scheduled to one hour to make the data gathering process very brief and involving rather than tense and longer. In a like manner, two owners of private health centers; Universal, and Abdi in Nekemte, and Adama Higher Clinic and St. Luke Clinic in Adama were contacted for data provision. Officers were selected based on their roles and responsiveness to represent their respective institutions. Such external stakeholders were selected to provide data regarding their roles to contribute in terms of supportive and evaluative remarks for private health institutions. Data from health bureau helped the researcher to assess provision on the part of the mentioned agency, to look into the professional and subject-area expertise due private health institutions as per the requirement of reforms in the objectives of health education and expected diversity in the health services.

\subsection{Data Sites}

Data sites were private health institutions providing health training and education. Target to this case were Central Health College, Rift-Valley University College, and Harambe Health College in Adama City; and, 
The role of different stakeholders in Ethiopia in the improvement of educational quality

Deborah Health College and Keamed Medical College in Nekemte. The researcher referred to these institutions for cases of possibility to get sufficient data and level-oriented information from diverse angles. So, the selection was purposive. Above all, their being accessible for visits and vitalization of data were apt to the selection of the institutes.

\subsection{Data Type and Sources}

For the realization of this research, both quantitative and qualitative data were used. The quantitative data included responses given to questionnaire where as the qualitative data included data collected through interview and documentary analysis. Questionnaire referred to students' reactions to their roles in learning, in improving their own learning and seeking better techniques of teaching, learning, communication, facility, and assessment. Teachers' interview referred to their planning, implementing, assessing and improving learning. Officers' interview rested on such issues as planned orientation on roles schools should play, mechanisms they use to communicate vertical and horizontal experiences that are beneficial to improve quality of learning and teaching. The researcher used the two instruments in such a way that the data would complement each other.

\subsection{Procedures and Techniques of Data Collection and Analysis}

The data were gathered in the procedure such that, first questionnaire data were collected. Next interview data or oral testimonies were collected so that it would be vital to assess documents on tangible bases. Third archival data were collected. Data analysis took the conventional data first and then the archival data. Both statistical and thematic techniques were employed in the data analysis.

\section{Organization and interpretation of the data}

\subsection{Organization and Analysis of Data from Internal Stakeholders}

The questionnaire dealt with issues internal and external to the private higher institutions with regard to quality assurance, staff involvement, college-customers' ties and research. the researcher has termed academic deans, teachers, students, administrators and health institutes directly working with the private health institutions "Internal" because these are directly involving agencies at least in time of field practice. The rest like hospitals under private holding which rarely work with health institutions but are more likely to be concerned as employers, advisors and other attachment providers have been termed "External Stakeholders". This presentation brings internal stakeholders' partaking first, and then goes to the contributions of the external.

\subsection{Key Issues of Concern and Response Index}

\section{Table 1}

Presence and Overall Working of Internal Quality Assurance

\begin{tabular}{|c|c|c|c|}
\hline Points of concern & Fully Present & Partly present & Totally absent \\
\hline Proper planning & $\begin{array}{c}4 \\
(100 \%)\end{array}$ & 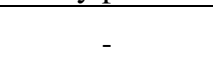 & 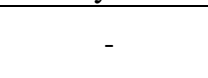 \\
\hline Activity and resource index & $\begin{array}{c}1 \\
(25 \%)\end{array}$ & $\begin{array}{c}2 \\
(50 \%)\end{array}$ & $\begin{array}{c}1 \\
(25 \%)\end{array}$ \\
\hline Follow-up schema & $\begin{array}{c}2 \\
(50 \%)\end{array}$ & - & $\begin{array}{c}2 \\
(50 \%)\end{array}$ \\
\hline Communicating feedback to customers. & $\begin{array}{c}1 \\
(25 \%)\end{array}$ & $\begin{array}{c}1 \\
(25 \%)\end{array}$ & $\begin{array}{c}2 \\
(50 \%)\end{array}$ \\
\hline
\end{tabular}

The above issue was raised to check the extent to which the private health institutes which were held in the research catchment had internal checking of their qualities in planning, implementation and evaluation. For this 
Kufi, E. F.

case, a four-point open-ended questionnaire was presented to the internal quality offices of the four colleges. Thematically set, while all the four colleges had a good quality assurance plan, only one had proper activity index and resource guideline, and the system of communicating its undertakings to its customers. In two sites $(50 \%)$, activity indices were partially present, and in one of the sites, the other $25 \%$, no activity index for quality follow-up was indicated. Asked to brief how they set out to materialize that communication, the officers replied that, they had guidelines which related to the requirement of the quality assurance based on which they developed schema for activities and durational follow-up. The highest rate of responses indicated very high attention given to plan, partially done activity index upon implementation, and very minimal follow-up and exchange of feedback held with customers. As the respondents denoted in their responses to the interview, assessment and feedback realms were set outside the climate of internal quality follow-up to the largest owing to overdependence on college owners' whims to drive matters in line with their sustained benefits and the tradition of preparing students for the competency test.

Table 2

Curricular Contributions of the Internal Stakeholders

\begin{tabular}{|c|c|c|c|c|c|c|c|c|c|}
\hline \multirow{2}{*}{$\begin{array}{c}\text { Points of the } \\
\text { study }\end{array}$} & \multicolumn{3}{|c|}{ Full participation } & \multicolumn{3}{|c|}{ Partial } & \multicolumn{3}{|c|}{ None } \\
\hline & $\mathrm{O}$ & $\mathrm{T}$ & $\mathrm{S}$ & $\mathrm{O}$ & $\mathrm{T}$ & $\mathrm{S}$ & $\mathrm{O}$ & $\mathrm{T}$ & $\mathrm{S}$ \\
\hline $\begin{array}{l}\text { Curriculum } \\
\text { development }\end{array}$ & $\begin{array}{c}1 \\
(25 \%)\end{array}$ & $\begin{array}{c}2 \\
(10 \%)\end{array}$ & - & $\begin{array}{c}1 \\
(25 \%)\end{array}$ & $\begin{array}{c}5 \\
(25 \%)\end{array}$ & - & $\begin{array}{c}2 \\
(50 \%)\end{array}$ & $\begin{array}{c}13 \\
(65 \%)\end{array}$ & $\begin{array}{c}40 \\
(100 \%)\end{array}$ \\
\hline $\begin{array}{l}\text { Curriculum } \\
\text { evaluation }\end{array}$ & $\begin{array}{c}1 \\
(25 \%)\end{array}$ & $\begin{array}{c}3 \\
(15 \%)\end{array}$ & $\begin{array}{c}4 \\
(10 \%)\end{array}$ & $\begin{array}{c}1 \\
(25 \%)\end{array}$ & $\begin{array}{c}3 \\
(15 \%)\end{array}$ & - & $\begin{array}{c}2 \\
(50 \%)\end{array}$ & $\begin{array}{c}14 \\
(70 \%)\end{array}$ & $\begin{array}{c}36 \\
(90 \%)\end{array}$ \\
\hline Research & - & - & - & $\begin{array}{c}1 \\
(25 \%)\end{array}$ & $\begin{array}{c}2 \\
(10 \%)\end{array}$ & - & $\begin{array}{c}3 \\
(75 \%)\end{array}$ & $\begin{array}{c}18 \\
(90 \%)\end{array}$ & $\begin{array}{c}40 \\
(100 \%)\end{array}$ \\
\hline $\begin{array}{l}\text { Innovative } \\
\text { feedback }\end{array}$ & $\begin{array}{c}1 \\
(25 \%)\end{array}$ & $\begin{array}{c}2 \\
(10 \%)\end{array}$ & - & $\begin{array}{c}2 \\
(50 \%)\end{array}$ & $\begin{array}{c}4 \\
(20 \%)\end{array}$ & - & $\begin{array}{c}1 \\
(25 \%)\end{array}$ & $\begin{array}{c}14 \\
(70 \%)\end{array}$ & $\begin{array}{c}40 \\
(100 \%)\end{array}$ \\
\hline
\end{tabular}

Note: $\mathrm{O}=$ Officers, $\mathrm{T}=$ Teachers $\& \mathrm{~S}=$ Students

From the above presented data, it is evident that, both college owners and teachers partially participated in curriculum planning whereas students had no tangible role. In curriculum evaluation as well, the three agents had minimal roles. Research works around curriculum were very weak as indicated in the data above. So minimal was the innovative input of internal stakeholders as well. As responses to the open ended questionnaire to interview indicated, failure to organize efforts emanated from three main sources or factors. The first source of impact, as the officers and teachers unanimously set, came from the very focus of the training which was meant for producing human resources for market in line with government guideline. The second came from the sentiments of college owners, as the responses indicated, where all days and weeks were meant for teaching the given curricula rather than dealing with the business of research and evaluation.

To reflect on this, the work of curriculum development and use in educational programs is dependent on the principle of cooperative endeavor (Oliva, 2009). Students and the community, teachers and curriculum specialists as professionals, administrators and the students who are direct beneficiaries from the program are parts of the stake-groups who play pivotal roles. These must be in collaboration for reasons of extensive undertaking and possibilities of bringing about non-weaning progress in education. Group consensus in work place can also be realized by involving such key stakeholders as well.

Table 3

Teachers' Nurturing of Students' Contributive Roles

\begin{tabular}{l|cc|cc|ccc}
\hline \multicolumn{1}{c}{ Options } & \multicolumn{2}{c}{ High } & \multicolumn{2}{c}{ Medium } & \multicolumn{2}{c}{ None } \\
& No. & $\%$ & No & $\%$ & No. & $\%$ \\
\hline Having due plan & 8 & $40 \%$ & - & - & 12 & $60 \%$ \\
Implementation & 4 & $20 \%$ & 4 & $20 \%$ & 12 & $60 \%$ \\
Evaluation & - & - & 3 & $15 \%$ & 17 & $85 \%$ \\
\hline
\end{tabular}

Teachers' nurturing of students' personal contribution for their own learning is a very essential process 
The role of different stakeholders in Ethiopia in the improvement of educational quality

(Laura \& Holdeide, 2010). In this research as well, a brief look was made into teachers' nurturing for students' active learning. In that, of the sampled 20 teachers, 8 (40\%) indicated having well-set plan to activate students' initiation to learn effectively by devising activities which inspire the latter to work hard and become creative problem-solvers. To the contrary, $12(60 \%)$ teachers indicated that, they didn't have such plans and implementation strategies owing, mainly, to basically predetermined trek to prepare students for the competency test. Here, it becomes essential to trace what works and what fails to in line with scholarly literature. According to Moore (2001), a teacher is a professional destined to play three distinctive roles. One such a role is being instructional expert; being so goes entirely with planning, guiding and evaluating learning. This is a core role supported by other roles. Perhaps, it is the leading aspect of the teachers' contributions as a stakeholder in education as well. In line with the above response given, teachers' lack of experiences or minimal experiences denote lack of good shareholding as well.

The second important role of the teacher is to be a manager, to order and structure the learning environment. Included in this role are all the decisions and actions required to maintain order in the classroom (Moore, 2001). But, in the research data above, teachers were less likely to have had both the tendency and the knowhow to have been said managers in their works. So, the situation was better to have said secluding the teachers' roles. Since learning is not just a perfection task, working on students' failure is also the other ingredient in being a teacher, and this makes up the professions' counseling role an issue of big concern. As seen in the data above, however, teachers did not seem to have had due roles in providing counseling services afoot. The other way round, planning, working with and evaluating learning through the consultation and day-to-day communication of learners also enriches experiential learning tendency, the quality for teachers to be models in their professions.

\section{Table 4}

Internal Stakeholders' Roles in Developing and Using Task Guidelines

\begin{tabular}{|c|c|c|c|c|c|c|c|c|c|}
\hline \multirow{2}{*}{ Options } & \multicolumn{3}{|c|}{ High } & \multicolumn{3}{|c|}{ Medium } & \multicolumn{3}{|c|}{ Low } \\
\hline & $\mathrm{O}$ & $\mathrm{T}$ & $\mathrm{S}$ & $\mathrm{O}$ & $\mathrm{T}$ & $\mathrm{S}$ & $\mathrm{O}$ & $\mathrm{T}$ & $\mathrm{S}$ \\
\hline Good resource plan & $\begin{array}{c}2 \\
(50 \%)\end{array}$ & $\begin{array}{c}4 \\
(20 \%)\end{array}$ & $\begin{array}{c}4 \\
(10 \%)\end{array}$ & $\begin{array}{c}2 \\
(50 \%)\end{array}$ & $\begin{array}{c}4 \\
(20 \%)\end{array}$ & $\begin{array}{c}4 \\
(10 \%)\end{array}$ & - & $\begin{array}{c}12 \\
(60 \%)\end{array}$ & $\begin{array}{c}32 \\
(60 \%)\end{array}$ \\
\hline Proper organization & $\begin{array}{c}2 \\
(50 \%)\end{array}$ & $\begin{array}{c}4 \\
(20 \%)\end{array}$ & $\begin{array}{c}2 \\
(5 \%)\end{array}$ & $\begin{array}{c}2 \\
(50 \%)\end{array}$ & $\begin{array}{c}4 \\
(20 \%)\end{array}$ & $\begin{array}{c}2 \\
(5 \%)\end{array}$ & - & $\begin{array}{c}12 \\
(60 \%)\end{array}$ & $\begin{array}{c}36 \\
(60 \%)\end{array}$ \\
\hline $\begin{array}{l}\text { Workable } \\
\text { dissemination }\end{array}$ & - & - & - & $\begin{array}{c}2 \\
(50 \%)\end{array}$ & - & - & $\begin{array}{c}2 \\
(50 \%)\end{array}$ & $\begin{array}{c}20 \\
(100 \%)\end{array}$ & $\begin{array}{c}40 \\
(100 \%)\end{array}$ \\
\hline $\begin{array}{l}\text { Reasonable } \\
\text { follow-up }\end{array}$ & $\begin{array}{c}4 \\
(100 \%)\end{array}$ & - & - & - & - & - & - & $\begin{array}{c}20 \\
(100 \%)\end{array}$ & $\begin{array}{c}40 \\
(100 \%)\end{array}$ \\
\hline
\end{tabular}

Administrative guide of staff to good resource plan, proper organization, workable orientation, use and direction were the other issues of concern in this research which were taken to be focal for underpinning quality resource use in education. In this regard, while all the administrative staff of the represented colleges had due resource plans, they seldom had programs to communicate their plans to the users of resources in which case 2 $(50 \%)$ of the respondent officers gave witness of communicating plans properly, and $2(50 \%)$ others didn't. Little attention was paid in three of the four colleges to workable dissemination on the part of the teachers and the students as well. Reasonable follow-up learning- teaching and educational processes overall was also minimal when seen from the standpoint of the teachers' and the students' roles. But, the realization of teaching and learning, proper use of technology and attainments of objectives are weighed in terms of teachers' and students' actions (Jacobsen, Eggen, \& Kauchak, 2009).

These scholars state that, the learning environments which teachers create and the role students' play make the arena of education a complete situation. From this it could be understood that, how strong the administration may be, the grandest accomplishment meets its doom when the three are not in collaboration. A certain working paper of UNICEF (2000), regarding quality education, states that, quality education, besides guarding learners' welfare and ensuring efficiency of programs, has to ensure the level to which students look into the process of learning right from the very beginning and shoulder the responsibility of being reflective. 
Kufi, E. F.

By far, issues said to be points of focus when craving for quality are learners who are healthy, well-nourished and ready to participate and learn, and supported in learning by their families and communities; environments that are healthy, safe, protective and gender-sensitive, and provide adequate resources and facilities; content that is reflected in relevant curricula and materials for the acquisition of basic skills, especially in the areas of literacy, numeracy and skills for life, and knowledge in such areas as gender, health, nutrition, HIV/AIDS prevention and peace; processes through which trained teachers use child-centered teaching approaches in well-managed classrooms and schools and skilful assessment to facilitate learning and reduce disparities; outcomes that encompass knowledge, skills and attitudes, and are linked to national goals for education and positive participation in society. Turning to the issues under research above, while planning and organization of guidelines were partially handled by all the stakeholders, dissemination(communication) and follow-up of use were found to have been very low.

Table 5

Using Knowledge and Experiences in the Field for Proper Lesson Delivery

\begin{tabular}{|c|c|c|c|c|c|c|c|c|}
\hline \multirow{2}{*}{ Options } & \multicolumn{2}{|c|}{ High } & \multicolumn{2}{|c|}{ Medium } & \multicolumn{2}{|c|}{ Low } & \multicolumn{2}{|c|}{ None } \\
\hline & $\mathrm{T}$ & S & $\mathrm{T}$ & $\mathrm{S}$ & $\mathrm{T}$ & $S$ & $\mathrm{~T}$ & S \\
\hline From hospitals & $\begin{array}{c}16 \\
(80 \%)\end{array}$ & $\begin{array}{c}25 \\
(62.5 \%)\end{array}$ & $\begin{array}{c}2 \\
(10 \%)\end{array}$ & $\begin{array}{c}3 \\
(7.5 \%)\end{array}$ & $\begin{array}{c}2 \\
(10 \%)\end{array}$ & $\begin{array}{c}12 \\
(30 \%)\end{array}$ & - & - \\
\hline From private clinics & $\begin{array}{c}2 \\
(10 \%)\end{array}$ & $\begin{array}{c}8 \\
(20 \%)\end{array}$ & $\begin{array}{c}4 \\
(10 \%)\end{array}$ & $\begin{array}{c}2 \\
(10 \%)\end{array}$ & $\begin{array}{c}2 \\
(10 \%)\end{array}$ & $\begin{array}{c}4 \\
(10 \%)\end{array}$ & $\begin{array}{c}12 \\
(60 \%)\end{array}$ & $\begin{array}{c}26 \\
(65 \%)\end{array}$ \\
\hline From pharmacies & 4 & ( & 4 & 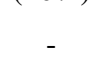 & $\begin{array}{c}10 \\
(50 \%)\end{array}$ & $\begin{array}{c}11 \\
(27.5 \%)\end{array}$ & $\begin{array}{c}10 \\
(50 \%)\end{array}$ & $\begin{array}{c}29 \\
(72.5 \%)\end{array}$ \\
\hline From health centers & $\begin{array}{c}11 \\
(55 \%)\end{array}$ & $\begin{array}{c}22 \\
(55 \%)\end{array}$ & - & - & $\begin{array}{c}9 \\
(45 \%)\end{array}$ & $\begin{array}{c}18 \\
(45 \%) \\
\end{array}$ & - & - \\
\hline
\end{tabular}

Data in the above table depict that, the highest number of benefits to the private health institutes came from hospitals while private health institutes such as clinics and pharmacies had very minute roles to provide for the former. In the face-to-face communication through interview, the researcher verified that, barrier in communication between private health colleges and private center owners was the result of labor clash where the latter were said to have requested extra-ordinary payments even to entertain a single candidate and that forced the former to levy extra payment on the candidates to which effect they missed many attendants.

Table 6

Inter-collegiate ties for Experiential Exchange

\begin{tabular}{clcccc}
\hline No. & Options & High & Medium & Low & None \\
\hline 1 & Academic Seminar & 1 & 1 & & 2 \\
2 & Research symposia & 1 & - & - & 2 \\
3 & Staff exchange & - & - & - & - \\
4 & Material exchange & 1 & - & - & 3 \\
\hline
\end{tabular}

As observed in the above table of data, among the four colleges the researcher contacted, only one had part in holding and partaking academic seminars, research symposia and material exchange with other colleges of similar undertaking; one more with medium status of research and the remaining two reported having no part in research. Scholarly works verify and validate research to be the best tool for higher education institutions to be clearly working for quality, to which health institutes are no exception. Regarding such a necessity Pollard (2005) states that, research is essentially needed in institutional plans, performance indices and anticipations of new ways of doing things. So, the data above had the chain of blocking all the virtues related to research on collaborative bases that must have been realized in both health organizations colleges of private health institutions; the rationale being that, decisions made without due footing on research are often hasty and untested on objective grounds. Collaborative research also helps to make use of the proximate resources that are often unrecognized. 
The role of different stakeholders in Ethiopia in the improvement of educational quality

\subsection{Regarding external stakeholders' contributions}

\subsubsection{Private Clinics and Pharmacies}

Regarding the roles of external stakeholders, some indicatives have been set as forerunner for the data and directions for analysis. Since most of the data were collected in a qualitative manner, the arrangement and interpretation also follows that form. Provision in terms of practice sites, evaluative supports, providing information on what can aid improvement of programs, and support in terms of career guidance and training.

\section{Provision of Practice Sites for Private Health Institutions}

As stated in the case of internal stakeholders, it becomes essential to co-plan before having co-action. so, the four private clinics the researcher contacted witnessed their not having any share of provision in spatial terms the causes being lack of awareness in the first place and the very reluctance on the part of the private colleges to work with nearby centers. A similar assertion followed on the implementation as well. The other point with respect to provision of practice sites and opportunities was that, some college owners resorted to their own health clinics and tended to have students get all the practices there. But, to verify if what the private centers of health asserted, the researcher contacted college administrators of the private fare who related the barrier in provision to lack of concern on the part of the former, and sometimes requesting very high payments, as aforementioned.

A specialist in one of the clinics asserted the following:

On my part I like, verily love to provide my long-year's experience to the candidates who are coming to the health profession; the problem is that, there is no such a tradition of knowledge-sharing. The institutes themselves never send their candidates for essential project work or research by far. Training for middle-level health work is also given by health officers, and we have a little of help to them...

In general, the above assertions denote an overall shortage in the service provision to private health institutions.

\section{Providing Evaluative Supports}

For the realization of education in higher institutes, the evaluative role of those in the workplace becomes essential for three main reasons, as indicated by Eric and Carol (1992). The first point goes to the exposition of experiences which make candidates alert to day-to-day needs that are manifest in the field. The second relates to the widening of the candidates' expectations regarding their respective profession. The third refers to the scientific inputs the candidates can provide to the areas of practice. Regarding this, the health centers and clinics referred to in the research, except the hospitals and government health centers, had no roles of evaluating the programs, practices and procedures of the private health training. This implies that, they both lack the experiences and lose the opportunity to get insight on what accounts reciprocal undertaking in education. Here, it must be noted that both the private health centers and colleges providing were at the negative side of experience because they failed to work in collaboration.

With regards to the gaining of knowledge from diverse sources, apart from what people gain through formal contacts, there is a need to get informal experiences as well as the formal. In support to this, Sharma (2004) states that, knowledge communities may have overlapping areas of interest as well as overlapping membership, and perhaps common knowledge requirements. For the best utilization of knowledge capital in and out of the organization, there must exists means of sharing and transforming knowledge. But, in the cases traced above, the private health colleges and private health centers did not have constructive ties.

\subsubsection{The Role of Hospitals}

With respect to the role of hospitals, the researcher treated cases pertaining to co-planning, experiential-sharing and provision of placement for practices, collaborative research, and resource-exchange. 
The data qualitatively set were presented as in the succeeding lines:

\section{Co-planning (Collaborative Planning)}

A successful plan is, by definition, a usable plan - one that informs the organization's activities as well as its long-range view, and one that yields meaningful improvements in effectiveness, capacity and relevance. This is true of plans and co-working of private health institutes, to which private health institutions in Ethiopia are no exception. The researcher had discussion with the medical director of Adama Hospital and administrative officer in Nekemte Hospital on the issues of exchange regarding plans between private health institutions and hospitals in improving education quality of the former. The participants reflected that, they had no co-planning tradition even though they lived proximate by location. The only means they had was students' practice session meant for placement purpose. Even that was highly limited to personalities who managed or monitored the practice, since not all specialists were given chances to mentor practices.

\section{Collaborative Research}

In today's world of science and technology, research in general and collaborative research in particular has paramount importance for the realization of both institutional and career goals (Trochim, 2004). According to this writer, research involves an eclectic blending of an enormous range of skills which the researcher must get through by working with a variety of people besides knowing what to study and how. Thus, in this research focus was made to the bilateral ties private health institutes may have had with hospitals. Hospitals in the research catchment were said to have had no such ties as of research, as reflected by officers of the two hospitals.

\section{Resource Exchange}

Interdependence between organizations in close connection on professional ties is very essential for mutual exchange and development. Resource exchange in terms of teachers and other related supports may be duly exchanged as the need arises. So, in this research focus was made to the efficiency of exchange in terms of human and material resources between hospitals and private health institutions in the research catchment. The responses given indicated that, the government hospitals and the private health institutions in the concerned research enclosure had no tangible relations organizationally. The respondents refrained to over-generalize personal absence of such as collaboration with the dubiety that, there might have been some professionals working for at their free time.

\section{Results and findings}

\subsection{Findings Regarding Communication of Curricular and Methodological Needs}

From the data treated in the research, it was clear that, internal stakeholders such as teachers, students, officers and deans in the concerned sites had very wide opportunities to look into plans and practices of their institutions than did the external stakeholders. The chain between private clinics and pharmacies was found to be very weak as well. In this regard, the researcher visited sample clinics thrice but found no affirming responses when it came to their collaborative contributions for education provided by private health institutions. The explication of cases pertaining to such a shortage is beyond the coverage of this research. Though internal stakeholders tend to be participating more, there lacks a chain of communicating curricular and methodological issues to be evaluated by students as the target beneficiaries. Even teachers haven't had full opportunity to evaluate and enrich curricula to the largest extent since generic coverage was emphasized. While communicating with certain college deans, the researcher has come to realize that, most of the teaching-learning tasks geared towards preparing students for the criteria examination than for rich cognitive development, to which effect curricular enrichment and process-oriented facilitations may have been taken as secondary. Yet, further research is required to verify the case. 


\subsection{Major Factors Affecting Stakeholders' Roles}

The affective factors could be divided into two: Positive and Negative. The very competitive nature of education provision as observed in the competency approach appears to have given positive grounds for teachers, leaders and students to work towards the destined end. Perhaps, as reflected in the qualitative data, the timely but non-coercive input of national quality assurance guideline is something worth-considering as progressive. The researcher has come to realize also that, the affects of such factors as lack of orientation on the necessity to contribute to quality, tense programming which sucks stakeholders' attention and deep emphasis on the product than process of education were the grand factors that negatively affected the role of internal stakeholders. The fact that, private colleges gave little emphasis to the role of private clinics and pharmacies, excepting a few, was also the other negative aspect which blocked mutual sharing of experiences in the academic and professional investment.

The fact that, private health institutions didn't have research centers, as there were no verifications for existence, may have had quite demarcating effects on their interactions with both external and internal stakeholders in an in-depth manner. In today's era of global competition and dynamism, lack of exchange ties such as research does mean lack of life breath. More specifically, the sites referred to in zones have never had research ties, and hence, they are more likely to be at disadvantage. Further research is required to verify this issue from the very ground.

\subsection{Collaborative Efforts and their Consistency}

The collaborative and interchange of college-stakeholders has the extent of being more internal than external and basically relied on casualty than systematic undertaking. From the researcher's very reference to the responses of teachers and students, and discussion held with deans and administrators, it was clear to gestalt that, most of the exchanges were pooled towards attaining some predetermined ends in the competency test. To this effect, the consistency of their interplay was also demarcated by the beneficence earmarked in that process. For instance, colleges had limited preliminary exchanges with hospitals except when they wanted practice sites. Teachers said they taught courses without interfering into program analysis or curriculum evaluation.

Private clinics referred to in both sites Nekemte and Adama reflected also that, they had little contributions for private health institutions because they were not called up to partake. Some private colleges have reacted however, that, even where the hospitals were benefitting in terms of practitioner resource, for which they were destined to pay, the reverse was said to have been done. Some hospitals tended to ask colleges for extra-payment. In this accord, there appears to have a misunderstanding between colleges and hosting sites such as hospitals or health centers. While exemplary efforts were observed in the collaborative stances of some private colleges such as Central University College and Keamed Medical College, in other colleges such as Deborah of Nekemte, declining conditions were observed owing to failure to activate college-stakeholder ties and the contributive effects thereunto. Further research is wanted to explicate the case.

\section{Conclusions and recommendations}

As observed in the research process above, private colleges had more internal than external ties when it comes to stakeholders' involvement in improving education quality. Even internally, the space given for students' and teachers' comments and evaluative remarks was very much limited. In a situation where solely academic and routine-based communication systems were used over and over, the internally driven support and experiential exchange between the private colleges and the stakeholders concerned was marred by lack of concern for co-planning and collaboration because each party was sensing to have been trekking alone to attain its destiny. While this research is inconclusive to suggest any further remedial, it becomes essential to point out that, the vitally necessitated relations in terms of internal and external knowledge and experiential resources have not been fully exploited in most of the situations. This is without knocking the innovative efforts and untiring 
Kufi, E. F.

commitments private health colleges have to bring improvement in the educated human resource.

\subsection{Recommendations}

Based on the analysis of questionnaire data complimented by summary and conclusions above, the researcher has given the following recommendations to guide efforts to be made to facilitate conditions for private health institutions to benefit from stakeholders, both internal and external, in terms of knowledge and experiences which will build education quality: 1.) Private health in the concerned catchment need to plan and work with both internal and external stakeholders such as professionals in private clinics, their own staff especially teachers and students and hospitals even more than now; 2.) The other point of concern is that, private health institutes need to extend their knowledge horizon through research; and, this will require them to have collaborative ties with other health institutions of the same nature or different ones as vital as they sense; and 3.) Further extensive research is needed to verify cases holding college-stakeholder ties back since the above research has taken only limited angles.

\section{References:}

Aligica, P. D. (2006). Institutional and stakeholder mapping: Frameworks for policy analysis and institutional change. Public Organization Review, 6, 79-90. <http://dx.doi.org/10.1007/s11115-006-6833-0 >

Brown, G., \& Atkins, M. (1991). Effective teaching in higher education. London: Routledge.

Brugha, R., \& Varvasovszky, Z. (2000). Stakeholder analysis: A review. Health Policy and Planning, 15(3), 239-246. <http://dx.doi.org/10.1093/heapol/15.3.239>

Cadora, L. (2008). Educational stakeholders. Retrieved from http://childlightusa.wordpress.com/

Colling, C., \& Harvey, L. (1995) Quality control, assurance and assessment: The link to continuous improvement. Quality Assurance in Education, 3(4), 30-34. <http://dx.doi.org/10.1108/09684889510098168>

Gawler, M., \& Golder, B. (2005). Stakeholder analysis. Retrieved from http://www.panda.org/standards

Gross, K., \& Godwin, P. (2005). Education's many stakeholders. Retrieved from http://www.universitybusiness.com

Halloway, W. (2000). Quality education in a global context. Retrieved from http://www.une.edu.au

Heidgerken, L. E. (2004). Teaching and learning in schools of nursing ( $3^{\text {rd }}$ ed.). New Delhi: Konark.

Materu, P. (2007). Quality assurance in sub-Saharan Africa: Status, challenges, opportunities and promising practices. Retrieved November 3, 2010 from http://www.wwwords.co.uk

Nichholls, G. (2001). Professional development in higher education: New dimensions and directions. London: Kogan Page.

Parri, J. (2006). Quality in higher education. Retrieved December 21, 2011 from http://www.leidykla.vu.it

Schmeer, K. (1999). Stakeholder analysis. Retrieved from http://www.who.int/management

Stanovich, P. J., \& Stanovich, K. E. (2003). Using research and reason in education. Retrieved October 11, 2010 from http://www.worldcat.org

Yizengaw, T. (2007). The Ethiopian higher education: Creating space for reform. Addis Ababa: St. Mary printing.

Yizengaw, T. (2005). Policy development in higher education in Ethiopia and the role of donors and develop partners. Retrieved June 3, 2011 from http://www.nuffic.nl/pdf/os/em/yizengaw.pdf

Trochim, W. M. K. (2004). Research methods ( $2^{\text {nd }}$ ed.) New Delhi: Biztantra.

Waghorn, A., \& Stevens, K. (1996). Communication between theory and practice: How student-teachers develop theories of teaching. Retrieved July 6, 2010 from http://ro.ecu.edu.au

Williams, J. (2002). The student satisfaction approach: Student feedback and its potential role in quality assessment and enhancement. Retrieved from http://www.bcu.ac.uk

Zhadko, O. (2009). What do you know about experiential education? Retrieved June 23, 2010 from http://coexchange.com 